\title{
REAL TIME DATA ANALYTICS AND DECISION MAKING IN ERP GAME SIMULATION: AN ACROSS DISCIPLINARY APPROACH
}

\author{
Ming Wang, California State University, ming.wang@calstatela.edu
}

\begin{abstract}
This paper presents a case study conducted in a business information systems course using SAP ERPsim games and business intelligence tools connected on SAP HANA, data in memory platform on cloud for real time data analytics and business executive report. The case provides students the opportunity to learn integrated business processes and strategies, real data analytics in the simulated enterprise environment and ERP technology. While the simulation game is running, students are able to visualize the change of the data in real time for decision making when they play the game. When the game is over, students are able to download the data generated from their business operations on the simulator to develop the executive data analytics report for their business strategies.
\end{abstract}

Keywords: ERP, SAP, IS Curriculum, Data in Memory, Business Processes

\section{INTRODUCTION}

Traditionally, the business information systems course often use case analyses to provide students opportunities to apply conceptual materials to industrial practice and to teach students data analytics skills with given sets of data. Lacking exposure, visualization, and hands-on practice in the real enterprise system environment, students learn the knowledge and skills to manage business information systems in an unnatural way. Using ERPsim provide the solution to the problem. The downloaded ERP data volume is large, but they are meaningful and interesting to students because they were from the game. Students are self-motivated to analyze them and eager to find out how their business strategies work in comparison with their competitors' companies. Thus, playing the ERPsim games is not only an engaging experience for students to learn business processes, management and strategies, but also a process for them to learn more on how to get the best analysis out of the integrated data in the enterprise system.

ERP is an enterprise system platform applied and implemented in most large organizations in the world. Over the years, there have been increased efforts to include more coverage of ERP systems in the business school curriculum (Antonucci et al., 2004). An entire issue on ERP education of the Journal Information Systems Education (JISE) with eight papers, one case study, and one teaching note was published in 2004. Hawking et al. (2004) indicated that in the 1990s there was considerable growth in implementation of ERP Systems. Many universities recognized this demand and the potential of using ERP Systems such as SAP as a teaching tool, and tried to incorporate ERP systems into their curriculum. Chen et al. (2015) empirically examined how ERPsim enhanced student learning outcomes in an IS course. ERPsim is an ERP teaching-learning simulator for business students to learn actual ERPSAP technology and business processes. The study provided empirical evidence that some major IS constructs (e.g., enjoyment and cognitive appraisal of using information systems) play important roles in shaping the effectiveness of using simulation game software to learn business processes and ERP SAP software. Kohers (2015) proposed to integrate ERP into IS cores based on the notable modifications to the Guidelines for Undergraduate Degree Programs in Information Systems (IS) with continuous emphasis towards ERP systems. Iriberri et al. (2015) obtained 230 valid student questionnaires in eight sections of the SAP course for analysis. Their findings indicated that participants had positive perceptions on the usefulness, ease of use, and intention to use the ERP system for the functionality of the system. Singh and Best (2016) also studied interactive visual analysis of anomalous accounts payable transactions in SAP enterprise systems.

Most ERP educators limit the scope of their ERP teaching to technical implementation and configuration issues, rather than addressing business strategies and data analytics issues based on the review of literature. Recognizing this curriculum design limitation, the author presents an innovative inter-disciplinary approach to teach business strategies and processes with real-time data analytics on HANA, the big data in memory platform on cloud 
computing. This case study introduces the four phases of the project. SAP ERP and Lumira utilized as software tools run on the ERPsim simulator. The teaching material resources are downloadable on the SAP University Alliances (UA) Curriculum Website and ERPsim Learning Portal.

\section{CASE PROJECT SUMMARY}

ERPsim Logistics Game (Léger et al, 2017) simulates in the real enterprise logistics environment. The students are assigned into teams (companies in the enterprise) in the Business Information Systems course. Each team manages a dairy trading company. Each company has its own main warehouse. The companies need to send products in their regional warehouses to sell them in the three respective regions in Germany. Thus, (1) they have to buy their products from their suppliers and (2) they need to distribute their products from their own main warehouse to their three regional storage locations. Companies must decide on and implement product transfer strategies. Success in the game depends on the company's ability to forecast the demand in each region for each product and plan procurement and product delivery accordingly. In order to learn the actual use of the ERP system to facilitate logistical processes, students implement material management and sales distribution in the game. The focus of the logistics game is on the integration of all its business processes. Students will learn how material planning, procurement, fulfillment, financial accounting and inventory/warehouse management processes are integrated and how these business processes interact with the financial accounting system in the enterprise environment.

\section{Case Phase 1}

Participants must manage the procurement process as well as the pricing and material transfers in the game. Figure 1 illustrate four main integrated business processes in the ERPsim Logistics Game (Léger et al, 2017). A business process is a set of logically related tasks performed to accomplish a business function (McKinney \& Kroenke, 2019). The four business processes are the material planning process, procurement process, allocation process, and sales process. The four roles to play in each team are planning manager, and materials management manager, sales manager and CEO. The SAP ERPsim simulation game will provide the ERP environment for students to experience an integrated enterprise system. Students are divided into teams. Each team will operate a logistics company that interacts with its suppliers and customers by sending and receiving orders, delivering its products, and completing the logistical cycle. Figure 1 illustrates the four integrated business processes in the ERPsim Logistics Game (Léger et al., 2017)

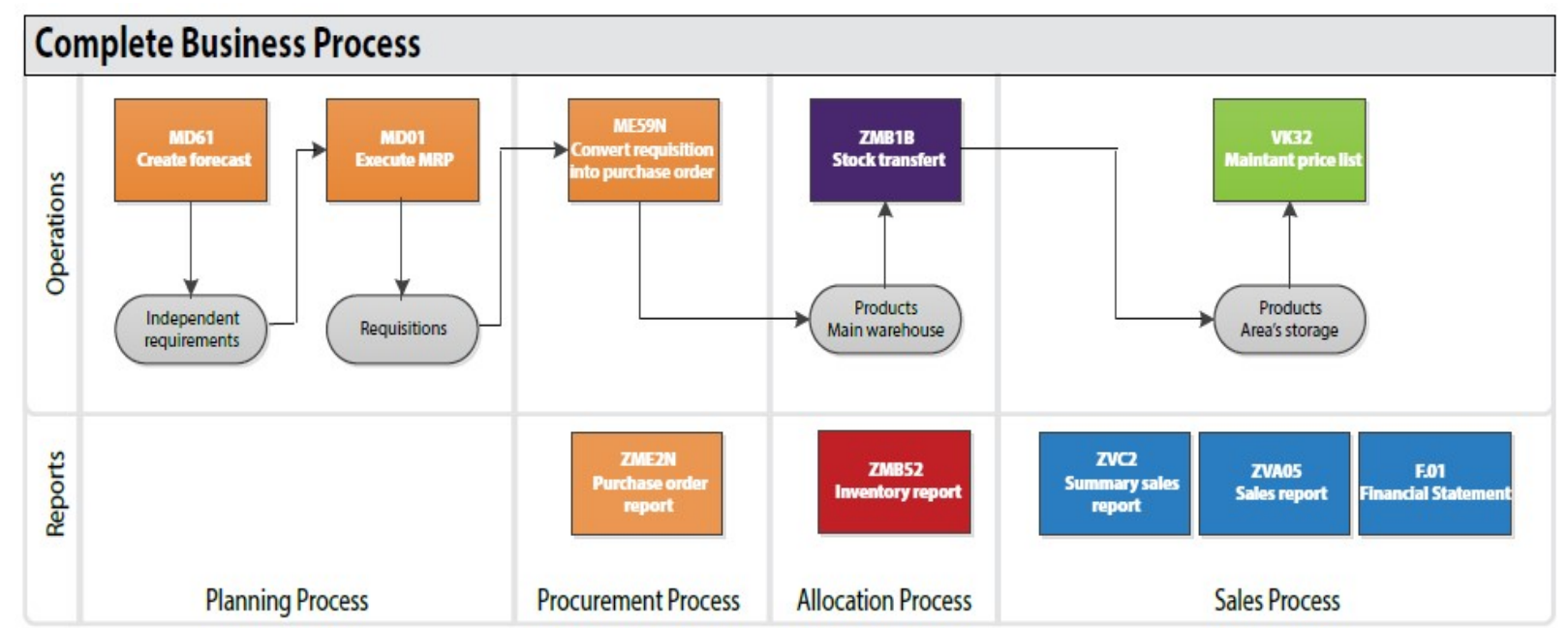

Figure 1. Integrated Business Processes in ERPsim Logistics Game

The first business process is the planning process managed by the planning manager. His/her responsibility is to forecast sales, calculate requirements (Run MRP) and create purchase requisitions. The second process is the procurement process managed by the material manager. His/her responsibility is to generate purchase orders and track them. The next process is the allocation process managed by the material manager. The main responsibility of 
the material manager is to determine a push or pull strategy to make sure the inventory in all of the storage locations stocked. The material manager can also generate an inventory report to see the levels of inventory. The last process is the sales process, managed by the sales manager. The sales manager is responsible for pricing the goods and generating summary and detailed sales reports. CEO reads reports and makes important strategic decisions for the company.

\section{Case Phase 2}

Students play the game in their roles while visualizing data changes in real time using SAP Lumira. The game simulator connected to SAP HANA on cloud will generate real time data from SAP HANA - a big data in memory database platform (Singh, 2015). HANA has columnar data storage instead of row data storage in traditional database. The advantages are better I/O bandwidth utilization, higher cache efficiency, faster data aggregation, high compression rates and column-based parallel processing. There are three views in HANA: Attribute View (Master data), Analytic View (information models) and Calculation View (Complex Calculations) (Bergand Silvia, 2014). Figure 2 illustrates real time data visualization from different perspectives analytic views on Hana in ERPsim.

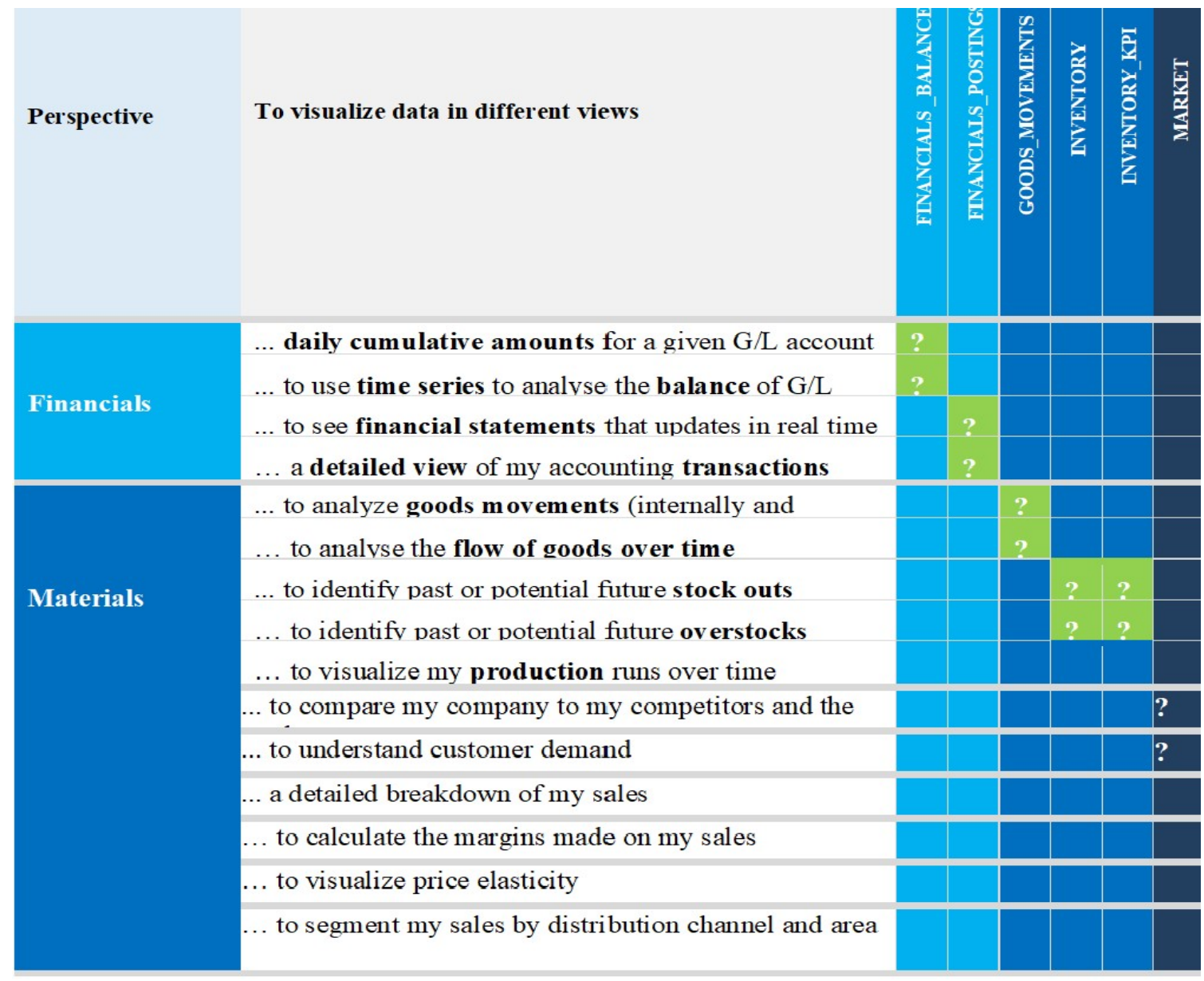

Figure 2. Data Visualization and Analysis in Real Time from Seven Views on Hana

\section{Case Phase 3}

Each student team will download data from SAP HANA directly, analyze the data and create their executive data analytical report. Figure 3 displays the total cumulative number of boxes sold over time for six products using the Dairy Sales cube. The cube contains the quantity sold by dates and products. Display the sum of quantity sold by date (in row labels) and by product description (in column labels). Figure 3 shows the sum of quantity, change the value setting and show the value as a running total (Robert, et al., 2013) 


\section{Issues in Information Systems \\ Volume 19, Issue 4, pp. 106-113, 2018}

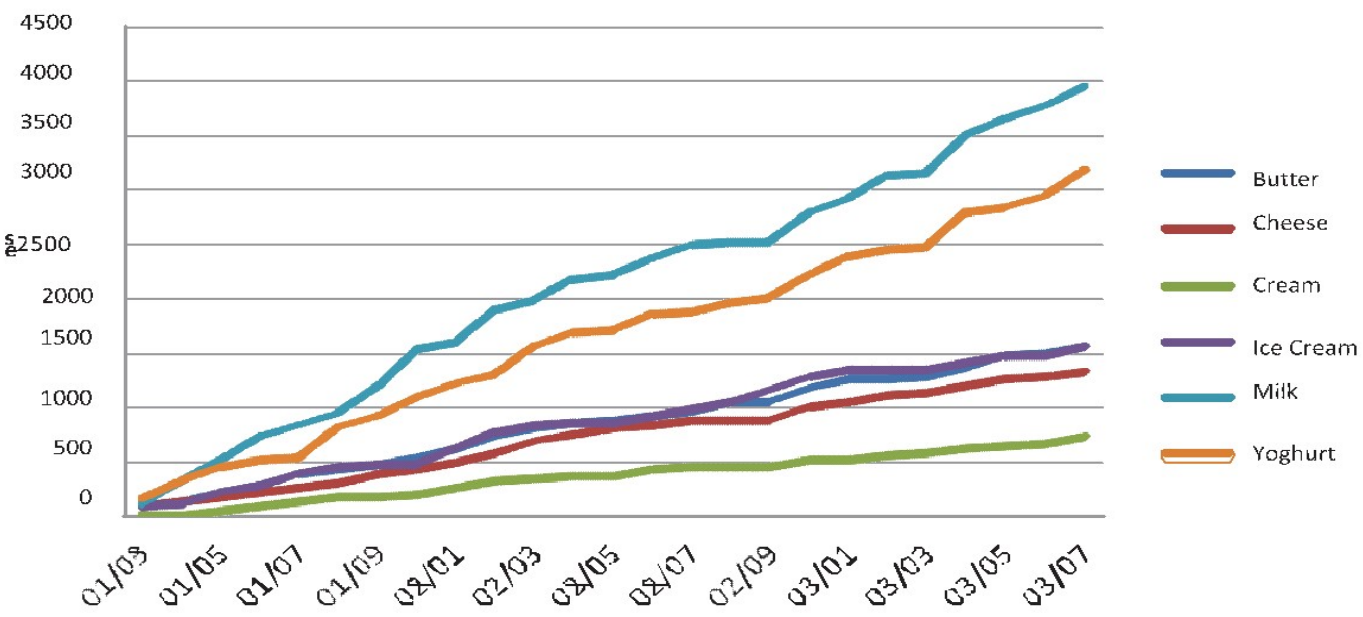

Figure 3. Sum of Cumulative Quantity Dairy Sales for Six Products

\section{Case Phase 4}

Business process modeling is a set of communication means utilized by the SAP team members in the blueprint phase. Business Process Model and Notation (BPMN) is the standard way of modeling and documenting business processes in most organizations. BPMN is a graphical representation for specifying business processes in a business process modeling. In this course, students will summarize the four main integrated business processes in the ERPsim Extended Logistics Game using the BPMN diagram as illustrated in Figure 4. The four roles played by each of the team members are CEO, Sales Manager, Materials Management Manager, and Planning Manager shown in the following BPMN.

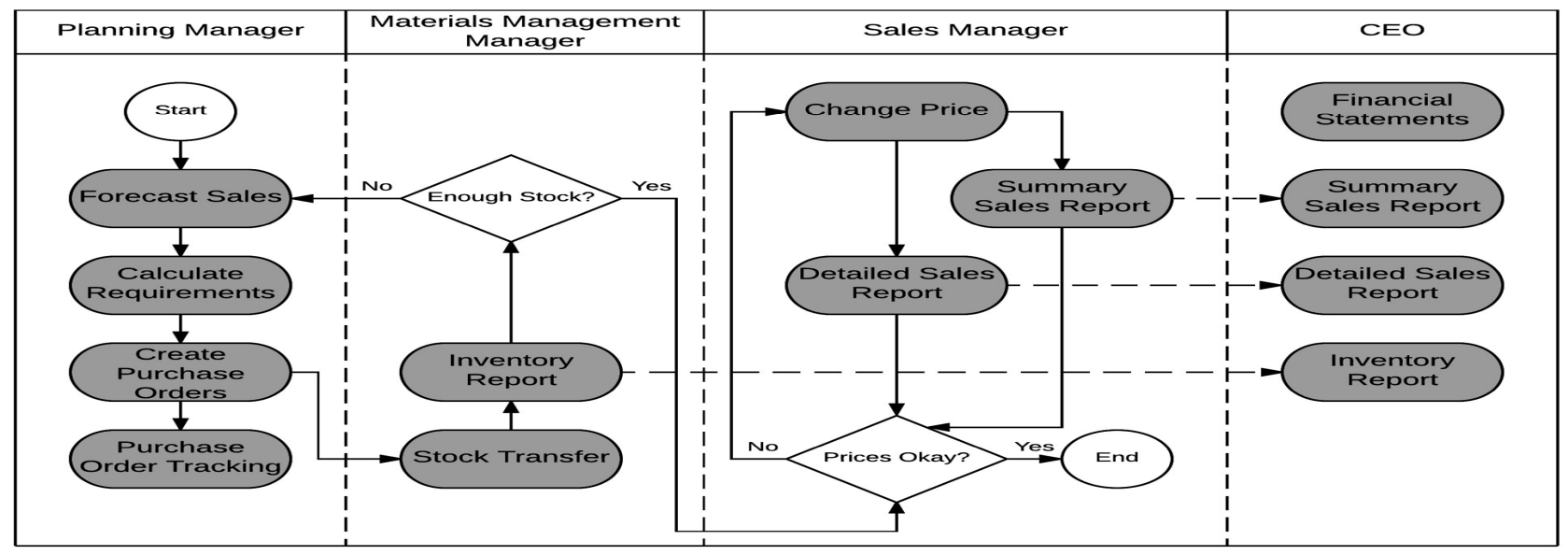

Figure 4. Integrated Business Processes in the ERPsim Distribution Game 


\section{METHODOLOGY}

\section{Phase One}

The instructor needs to connect the SAP GUI client to the hosted ERPsim server, assign student team accounts and start the Logistics Game Simulator on the Internet to set up the SAP enterprise logistics environment. Students will play in their roles in the game to learn the business processes in the ERP system.

\section{Phase Two}

Students will play in their roles in the game while visualize real time data change in Lumira in the classroom.

- Students connect HANA using Lumira and add new data sets to Lumira.

- Students log into the logistics game client and play the game

- Students set the variables in data sets, then click on the CREATE chart button.

- Students select the measures and dimensions for visualization and drop them into the chart.

- Students play the game while watching the data changes in the charts in Lumira.

- The instructor reveals the game competition result and open the discussion on it in the class.

\section{Phase Three}

The instructor downloads the simulation data from HANA to Access or SQL Server and demonstrates how to use transfer data among different data analytical tools and how to implement the tools.

- Students clean data in the Access database downloaded from HANA.

- Students convert data to Excel worksheet and then import them into Lumira.

- Students develop the executive data analytics reports.

Students are also able to connect any data generated from their business operations in the company from HANA directly to perform executive data analysis using SAP Lumira, Predictive Analysis or BusinessObjects.

\section{Phase Four}

Students draw BPMN to summarize the tasks they played in their roles for business process modeling.

\section{CASE PROJECT REPORT REQUIREMENTS}

Part 1. Write an enterprise executive report to analyze the ERP data downloaded the ERPsim Simulator.

- $\quad$ Read ERPsim SAP HANA Reference Guide (Michon, et al., 2017).

- Connect the company data in the seven views on Hana using data analytical software tools.

- Each team member creates two data visualization stories based on his/her role in the game.

- Summarize the company's business strategies based on the data analytical reports.

Part 2. Analyze data to compare the performance of your own team and winner's team by using data analytical tools. The enterprise executive report should be supported by the data in downloaded the game simulator.

- Import all the enterprise data downloaded from HANA by the instructor

- List and draw daily inventory for each product in companies. How many days are your company and the winner company out of stock?

- $\quad$ List and draw daily sales quantity and value amount for each product in different areas (NO, SO, and West) in your company and the winner company.

- List and draw daily price changes for each product in your company and the winner company.

- List and draw daily market investment for each product in different areas (NO, SO, and West) in your company and the winner company.

- What is the correlation between price and sales/profits for the whole enterprise?

- What is the correlation between market investment and sales/profits for the whole enterprise?

- Which company is the winner? What is its operation strategy for success?

- What is the new strategy for your company in the next game? 


\section{SAMPLE SOLUTIONS TO REAL TIME DATA ANALYTICS IN THE PROJECT CASE}

Part One: Using the Inventory Report, Planning Manager decides on products in each storage location that need and come up with a forecast number for procurement. Once procured products are ready in main warehouse, the material manager will distribute the products to corresponding storages. With reference to the goods movement report, he can move any product to the storage location where the product is running out. While the products being distributed to different storage locations, the sales manager will review the sales and marketing reports to decide on the need to update prices. SAP analytical tools allow analysts and decision makers to access, transform, and visualize data in real time on HANA.

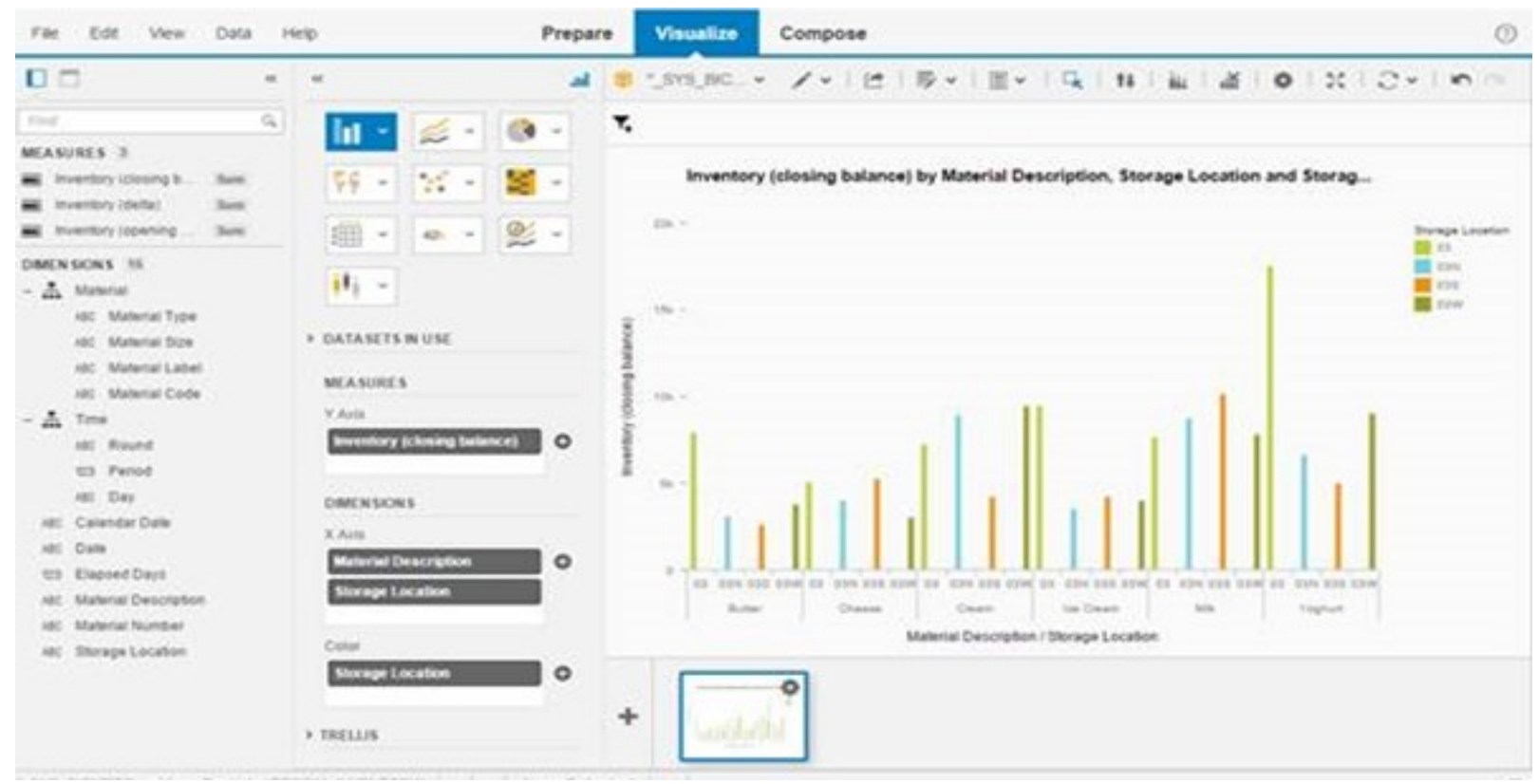

Figure 5. Real-time Inventory Data Visualization in Lumira

Part Two: Students develop the executive data analytics reports by answering those eight questions in the previous section. Figure 6 shows the changes of revenue between Team PP and Team MM in three rounds. Team PP compares their revenue data to Team MM's ones. Team MM is the winner team.

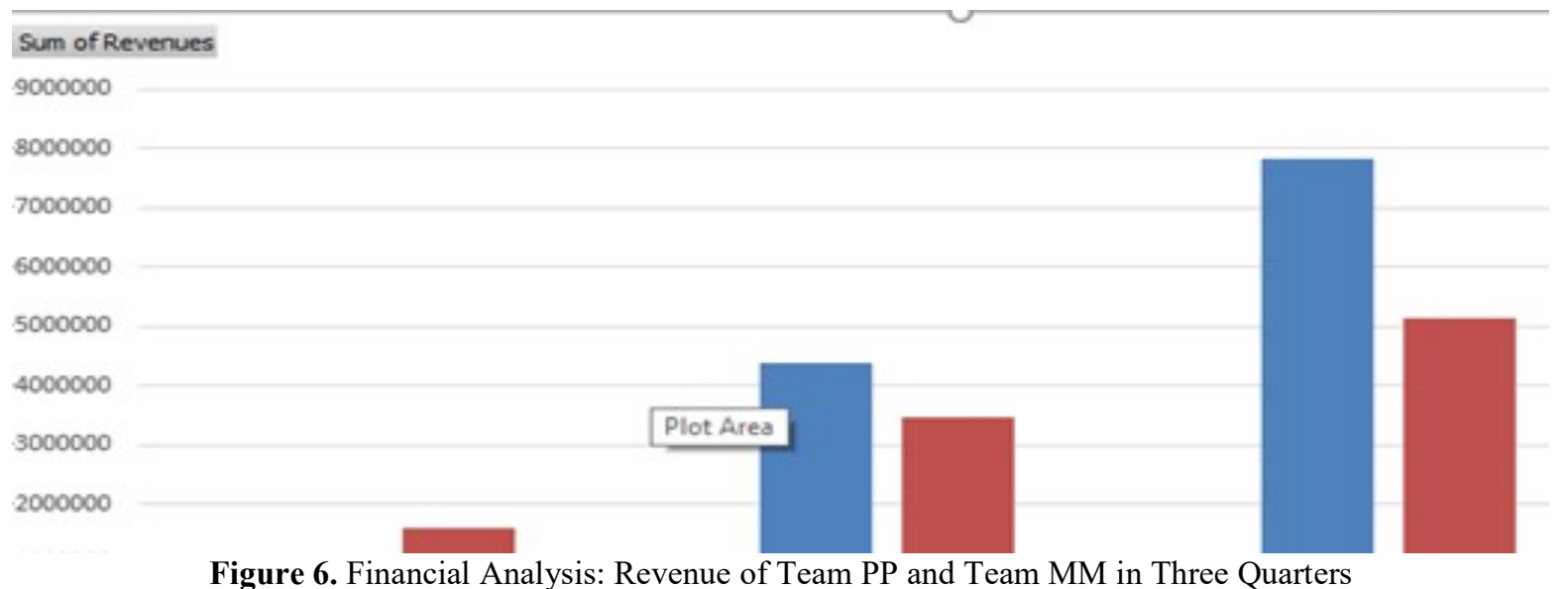

Figure 6. Financial Analysis: Revenue of Team PP and Team MM in Three Quarters 
DISSCUSSION

In this paper, the author presents an inter-disciplinary approach to teach the business information systems course. By adopting this approach, the IS educators are able to teach the fundamental ERP concepts and skills, business strategies and processes, and real time data visualization and analytics techniques in the course. The significant impacts will be on students' recruitment, job placement and career development. This inter-disciplinary approach follows the IT industry trend that shifts from the development of traditional functional applications to the enterprise systems.

\section{Paper Contribution}

The contribution of the paper is the development of the project executive report requirements. The report requirements will provide an important and practical guideline for students to integrate business strategies and processes, ERP technology and data analytics into their executive projects. This study provides an innovative interdisciplinary approach to teach the business information systems course and to meet the global shortage of next generation business leaders and IT professionals in the digital business world.

\section{Implementation Recommendations}

Learning by doing enterprise systems is important in teaching the next generation of digital business leaders. The student engagement with hands-on case activities needs to be in the organizational context. Thus, ERP software is vital to facilitate effective pedagogical methodologies for IS education such as hands-on experience, case study, technical implementation, and simulation. For illustration purpose, the study currently is ERP SAP software orientated. Institutions can certainly choose other ERP software packages such as JD Edwards, Oracle, PeopleSoft or Microsoft Dynamics. Thus, general usability of the study is evident. Learning one ERP software package helps students to understand the fundamentals of other ERP software packages. Meanwhile ERP vendors always invent new technology and analytical tools, IS educators need to keep learning and bring them into the classroom.

The author recommends IS instructors test the connection of multiple systems: SAP Server, ERPsim Server and HANA on cloud and data analytical tools before the class. The instructor will not be able to run the case study if the connection of servers fail. The author also recommends the IS instructors closely follow the update on the ERPsim learning portal to keep themselves updated with new technology and learning materials.

\section{Future Research and Improvements}

As previously mentioned, the author built the study on the extensive curriculum development experiences, marketleading ERP technology skills, and the consistent publication record in pedagogical referred journals in the past decades. The study, although practical, is yet to improve. The executive report guideline needs to be tested in multiple classes in different institutions. In the future, the author plans to collect both quantitative data and qualitative narratives from instructors who have adopted this approach in their teaching and research. With constructive feedbacks, positive experiences, and lessons learned, the author hopes to be able to improve this study and make it more effective in integrating business processes and strategies, ERP technology, and data analytics into in the information systems curriculum.

\section{REFERENCES}

Antonucci, Y., Corbitt, G., Stewart, G., \& Harris, A. (2004). Enterprise systems education: Where are we? Where are we going? Journal of Information Systems Education, 15(3), 227-234.

Berg, B and Silvia, P. (2014). SAP HANA: An Introduction Book, $3^{\text {rd }}$. Edition, SAP Press.

Chen, L., Keys, A., \& Gaber, D. (2015). How does ERPsim influence students' perceived learning outcomes in an information systems course? An empirical study. Journal of Information Systems Education, 26(2), 135 146. 


\section{Issues in Information Systems}

Volume 19, Issue 4, pp. 106-113, 2018

Hawking, P., McCarthy, B., \& Stein, A. (2004). Second wave ERP education. Journal of Information Systems Education, 15(3) 327-332.

Iriberri, A., Kwon, O., \& Henson, J. (2015). Integrating an ERP into the curriculum at a business school: The students' perceptions of SAP. Academy of Educational Leadership Journal, 19(2), 99-108.

Kohers, G. (2015). SAP and the introductory management information systems course. Academy of Educational Leadership Journal, 19(1), 65-70.

Léger et al. (2017). ERPsim Logistics Dairy Participant's Guide, ERPsim Lab, HEC Montreal, Canada, https://erpsim.hec.ca (Login user id and password are needed to access the guide

McKinney, E., \& Kroenke, D. M. (2019). Processes, systems, and information: An introduction to MIS (Third Edition). Upper Saddle River, NJ, USA: Pearson.

Michon, et al., ERPsim for SAP HANA Reference Guide, ERPsim Lab, HEC Montreal, Canada, 2017.

Robert, et al., Business Analytics for Simulation Games in SAP Using ERPsim to create dashboards, mine data, and win using business intelligences, HEC Montreal, Canada, 2013.

Singh, V. (2015). Real Time Analytics with SAP HANA, Packet Publishing, UK.

Singh, K., \& Best, P. (2016). Interactive visual analysis of anomalous accounts payable transactions in SAP enterprise systems. Managerial Auditing Journal, 31(1), 35-63. 